\title{
The Sustainability of Public Finances in Spain
}

\author{
Manuel Jaen Garcia ${ }^{1}$ \\ ${ }^{1}$ Universidad de Almería, Spain \\ Correspondence: Manuel Jaen Garcia, Universidad de Almería, Carretera de Sacramento s/n. 04120 Almeria, Spain
}

Received: September 16, 2020

Accepted: October 19, $2020 \quad$ Available online: October 23, 2020

doi:10.11114/aef.v7i6.5054

URL: https://doi.org/10.11114/aef.v7i6.5054

\begin{abstract}
Concern regarding deficits in the public accounts in Europe and the United States has led politicians and researchers to consider sustainability of fiscal policy understood as the fulfillment of the intertemporal budget constraint established by the government which indicates the extent to which accumulated and future debt can be paid for by means of current and future taxes, and also cover standard public expenditures.

The present article analyzes the sustainability of the national deficit in Spain for the period 1960-2016 by considering public revenue and spending in both real terms and percentages of gross domestic product using data from diverse Spanish sources. It utilizes the equations formulated by Quintos and adapts them when using variables as percentages of gross domestic product. This work concludes that Spanish debt is barely sustainable, which implies the need to instate fiscal reforms or, at least, make an effort towards consolidation.
\end{abstract}

This result is accord with the situation of Spanish debt and deficit in the period after the crisis of 2008.

Keywords: public finance, public deficit, expenditures, revenues, sustainability

JEL Classification: H11, H50, H62

\section{Introduction}

The recurring presence of deficits in the finance of Spain's public sector's, specifically as of the 1980s, and the resulting increases in public debt represent common concerns for both politicians and researchers. This preoccupation has drawn attention to public finance sustainability, understood as the fulfillment of the intertemporal budget constraint established by the government which indicates the extent to which accumulated and future debt can be paid for by means of current and future taxes, and also cover standard public expenditures.

Furthermore, the effectiveness of automatic stabilizers depends on the degree of sustainability of public finances in the long term. A substantial accumulation of public debt in the long term compromises the capacity of public budgets to act as a countercyclical mechanism to stabilize the economy (Correia et al., 2008).

According to Quintos (1995), fiscal policy is restricted by the need to finance the deficit, and any deficit trend will be sustainable if it is possible to borrow without restrictions and thereby finance debt interest through borrowing. However, a government which operates in a dynamically efficient economy balances its budget by intertemporally fixing the real value of its debt to the discounted current value of expected future budget surplus. Any violation of this rule would indicate that fiscal policy cannot be sustained indefinitely because the value of the debt would explode over time at a faster rate than the growth rate of the economy itself. Therefore, a sustainable fiscal policy is one whose discounted value tends to be zero at the limit, meaning the restriction of the current value of the debt will hold. Similarly, the real market value will be equal to the current value discounted from the flow of expected basic surplus.

The various treaties of the European Union (EU) (e.g., Maastrich and the Stability and Growth Pact) have fixed limits on both deficit and public debt. However, the recent events that brought about the Great Recession have called the sustainability of debt into question not only in Spain but in many EU countries as well.

Following the works of Quintos (1995), Camarero et al. (1998) and De Castro (2005), this article analyzes the sustainability of Spanish public debt. Section 2 contains a brief analysis of the recent evolution of public finances in Spain, while Section 3 cites the most notable works carried out in the field. Section 4 presents the theoretical model and offers the empirical test for Spain, and Section 5 presents the conclusions of the study. 


\section{Recent Evolution of Spanish Public Finances}

In recent times, public spending in Spain has experienced an intense increase in terms of both current prices and constant prices or percentages of gross domestic product (GDP). During the period 1960-2016, which is the study period of this research, four distinct phases can be identified according to their nature with respect to public spending (Tamames, 2005; González, 2013; García Delgado, 2015).

The first phase lasts from 1960 to 1975, and, during this time, public spending in real terms was less than 25\% of GDP. This figure remained below $20 \%$ of GDP during the initial part of the phase (19.5\% in 1965), unlike in the rest of the countries in the future European Union $15(33.1 \%)$ and the organization for economic co-operation and development (OECD) (26.9\%). Towards the end of the phase, public spending slightly surpassed $20 \%$ (24.1\% in 1975), albeit at the time the percentage in the Eurozone was $40.9 \%$ and in the OECD $34.4 \%$. State intervention in the economy was carried out through regulation, namely by means of laws and regulations. In the 1960s, industrialization helped public spending to grow. In the tradition of Wagner, economic development grew alongside increases in population, education, urbanization, healthcare and redistribution of revenue.

The second phase, between 1976 and 1985, saw a rapid expansion of public spending in Spain. Said expenditure rose from $23.19 \%$ of GDP to $42.5 \%$, in line with other OECD countries, whose average spending was $47 \%$ of GDP. This phase can be subdivided into two stages, the first of which (1975-1982) witnessed intense public spending growth, registering an accumulative annual rate of $25.5 \%$, which can be attributed to three factors (Alcaide, 1988): the political transition, the manifestation of the most severe consequences of the economic crisis, the existence of weak governments formed by the Union of the Democratic Center (UCD, in Spanish) and the strong opposition of the Spanish Socialist Workers' Party (PSOE), in Spanish). During the second stage, although growth continued at an accumulative annual rate of $15.3 \%$, it was lower due to various factors, most notably the lower intensity of the economic crisis; the existence of an absolute parliament majority, of the country's governing party; a consolidated democratic regime; and, above all, the beginning of an economic recovery phase during the latter part of 1985.

Considering this period in its totality, there is a consensus among various experts that the fundamental causes of the expansive evolution of public spending during this time were: 1) the political regime change and the transition agreements, given that the transition to democracy provoked a boom in the social demands that had been withheld during Franco's regime ${ }^{\mathrm{i}}$; 2) the economic crisis which forced the state to concede subventions to companies in the form of capital transfers; 3) the persistence of the budget deficit and its new financing model which substituted the seigniorage system, through the Bank of Spain, for the emission of public debt and market negotiations; 4) the decentralization of certain spending competences without any corresponding yielding of fiscal responsibility to the Spanish Autonomous Regions ${ }^{\mathrm{ii}}$ and, 5) budget laxity.

Simultaneously, the economic crisis caused an increase in unemployment. This problem was mitigated by the distribution of unemployment benefits to workers and, to a lesser extent, early retirement initiatives paid for by funds from the Social Security system to workers in declining industries, such as blast furnace industries, steelworks and shipyards.

The third phase (1986-1993) is one of the most important in Spain's recent history as it began with the country entering the European Economic Community and ended with the implementation of the first convergence program. In 1993, public spending represented $49.66 \%$ of GDP. As stated by Valle (1996), no other experience of this kind has taken place in other countries in which, in only twenty years, the proportion of total public spending (non-financial) nearly doubled. Such evolution reveals that Spain's development strictly followed the principles of Wagner's Law. This period also saw the consolidation of the country's system of autonomous regions, which meant that the management of this enormous spending growth gradually fell upon fledgling public administration institutions that were being established at the same time, thereby combining a lack of experience with the assumption of new competences. Valle also states that a large number of the problems in the Spanish revenue system are due to the lack of modernization that the rise in spending and its structural change would have required to secure adequate management and control of public spending.

Spending growth in Spain was the result of the policies instated by the new government controlled by the Spanish Socialist Workers Party (PSOE) to establish a welfare state in Spain. The universalization of public healthcare and the increase in the number of pensioners through non-contributive pensions, as well as the rise in the number of pensions themselves, were the main causes of growth. Similarly, education became compulsory until the age of 16 and agreements were made with the private education system by which the latter would receive subventions from the state in order to guarantee that education would be free for those between the ages of 6 and 16. Finally, the consolidation of the autonomous regions system took place - these smaller regional governments gained competences from the central government and assumed the corresponding expenditure requirements. Altogether, these factors produced a substantial increase in spending and a deterioration of the budget balance. In the final phase of this period, the absolute necessity to 
meet the requirements established by the Maastrich Treaty obliged Spain to reduce its deficit, after having reached its highest value with respect to GDP in 1993 (5.9\%).

The four phase can be split in diverse periods. Between 1994 and 1998 a drastic change took place in the Spanish public sector. Conceptually, it was a response to the change in economic paradigm from the post-Keynesian social democratic model to the neoclassical liberal system. The basic reasons for this change lied in the need to meet all the conditions of the Maastrich Treaty and the Stability and Growth Pact (SGP), in conjunction with the fact that this period coincided with the beginning of the expansion phase of the economic cycle in 1996. The once high budget deficits (7.3\% of GDP in 1994) fell to $2.6 \%$ in 1998, strictly complying with the particular conditions of the SGP (3\%). The most significant results of these government policies include the consolidation of economic recovery over the course of 1994, the increase in employment, the correction of disequilibrium in the balance of payments, salary moderation, and advances achieved in the reduction of inflation and public deficit.

The period between 1999 and 2007 saw the consolidation of Spain's public finances due to the Stability and Growth Pact, eventually leading to the country entering the Economic and Monetary Union (EMU, 2002) and the real estate bubble, which allowed unprecedented growth. Thus, a balanced budget was achieved in 2001, but public spending represented 40\% of GDP, which translates to a 4\% increase with respect to the average of the period 1997-2001.

The period prior to the bubble enabled strong employment growth along with an enormous increase in housing sales. In turn, the latter gave rise to an increase in tax revenue, both directly from personal income tax thanks to more employment in construction and other sectors, and indirectly from the value added tax from the sale of new housing and estate taxes on the sale of used homes.

A severe drop in the Spanish economy took place between 2008 and 2016 as a result of the real estate bubble bursting. Initially, expansion continued and Spanish GDP reached the average of the EU 27. At that moment, the fall of the United States and Europe's economies and its own internal problems cause the Spanish economy to enter a severe recession, which the country has finally begun to emerge from, displaying some positive growth in GDP (1.4\% in 2014 and 3.3\% in 2016) and high budget deficits (5.97\% in 2014, 5.28\% in 2015 and $4.51 \%$ in 2016).

Even though current public spending in Spain has risen in relation to previous periods, there is a difference with respect to the other European countries in the OECD. In 1960, the ratio with regard to GDP was $19.8 \%$, while in other European countries ${ }^{\mathrm{iii}}$ it was $29.5 \%$, and $26.6 \%$ in the OECD as a whole. In 1990 , the ratios were $46.3 \%$ for the EU, $38 \%$ for the OECD and $41.4 \%$ for Spain; while, in 2016, the ratios reached $48.1 \%$ for the EU27, $49.2 \%$ for the EU15, $41.2 \%$ for the OECD, and $43.6 \%$ for Spain.

A study of public revenue in Spain can be conducted in parallel to the evolution of its public spending. Until the reforms which began in 1977, the Spanish tax system corresponded to what is known as a Latin system based mainly on the taxing of specific goods, such as rural and urban real estate, movable assets, and business activities; encompassing work, capital and services. This system was complemented by income taxes. In 1986, coinciding with Spain's entry into the European Union, the valued added tax (VAT) came into force and substituted the old cumulative sale tax system which taxed each transaction in the production process.

Until the previously mentioned reforms of 1977, indirect taxation widely dominated over direct taxation. More specifically, direct taxes corresponded to $71.7 \%$ of indirect taxes in 1958. This trend continued in the years that followed until said reforms arrived. For example, indirect taxation represented $70.18 \%$ against $29.82 \%$ direct taxation; yet, by 1980 this distribution has nearly become balanced, reaching $50.89 \%$ and $49.11 \%$, respectively. In 2016, in terms of all taxes, indirect taxation accounted for $47.4 \%$ and direct taxation $52.6 \%$.

Prior to these reforms, the Spanish tax system did not respond to European guidelines: fiscal pressure was very low and its structure was different. Following the modifications, the system gained in equity, flexibility, neutrality and transparency and it assimilated to the methods of community member countries (Serrano and Bandrés, 2015).

In 2016, the revenues of the Spanish public administrations were derived from three sources: imputed social contributions (33.8\% of all public revenue), direct taxes (28.3\%), and indirect taxes (27.4\%).

Overall, fiscal pressure in the Spanish economy reached the figure of $40.9 \%$ of GDP in 2007, similar to the OECD average and three points below the European average. In 2011, the crisis situation of Spain's economy, set upon the backdrop of the European crisis, caused revenues to decrease, falling to $36.1 \%$ of GDP. In recent years, there has been a slight recovery of public revenues, rising to 38.9\% of GDP in 2014.

This tax decrease, along with the rise in public spending, brought about an increase in the public deficit, which rose from 1.9\% of GDP of surplus in 2007 to $9.6 \%$ of deficit in 2011, reaching a maximum of $11.0 \%$ of GDP in 2009. The austerity measures of the last government situated the deficit at 6\% of GDP in 2014. 
The evolution of the public deficit directly influenced the path of debt. Until the 1980s, debt remained below 30\% of GDP, but a sharp increase occurred during this period due to a rise in spending and the inability of the Spanish economy to expand its tax collection. By 1990, debt had already risen to 45\% of GDP and, although attempts were made in the following years to gain control of the situation, by 1995 it had reached $65 \%$. The need to meet the conditions of the Maastrich Treaty (60\% GDP) sank the economy even further in 1998 and the years that followed. However, this scenario eventually did improve thanks to strong growth driven primarily by the construction sector, which in 2008 managed to reduce debt to $39.5 \%$. Nevertheless, that same year marked the beginning of the Great Recession, at which time debt began to rise uncontrollably, reaching $60.1 \%$ in $2010,85.7 \%$ in 2012, and its highest figure of $100.4 \%$ in 2014. As of that year, a gradual decline commenced as a result of improved economic growth, reducing debt to $99 \%$ of GDP in 2016.

The recession of 2008 led to a public debt crisis in Spain which began in 2010. So critical was the situation that intervention by the European Union was initially required, followed by that of the European Central Bank (ECB). The crisis resulted in the high differential between Spanish and German public debt, also known as the risk premium, which began at very low and even negative values: -1 basic points in 2006 and 9 in 2008. From 2008, a dramatic increase began which elevated the premium to 94 basic points in 2010, 353 in 2012, and its maximum value of 574 in July 2012. At that point, thanks to the intervention of the ECB and its acquisitions in the public debt market, the premium decreased to a value of 204 basic points in January 2014 and later to 118 in December 2016.

\section{Review of Empirical Test}

Since the 1980s, a great deal of research has been devoted to the evaluation of the sustainability of fiscal policy and the solvency of government solvency. Among these works, special mention must be given to Hamilton and Flavin (1986), who investigated the testable implications of the current value constraint. Other notable studies which continued in this line are Wilcox (1989), Hakkio and Rush (1991), Haug (1991), Smith and Zin (1991) and Trehan and Walsh (1988, 1991). All consider the properties of the time series, unit roots and cointegration of the variables involved and, in the studies by Trehan and Walsh, any possible structural breaks in the data. The article by Quintos (1995) represents a breakthrough with regard to the other works in the sense that it introduces the concepts of strong and weak conditions in order for deficit sustainability to be possible and considers any possible structural breaks in the range of the cointegration matrix versus structural breaks which occur in the parameters of the cointegration vector.

Other works in keeping with Quintos (1995) include articles by Camarero et al. (1998) and De Castro (2005).

The first analyzes the two concepts of fiscal policy sustainability mentioned earlier and conducts the empirical analysis considering the possible presence of changes in economic policy regime. It does so by detecting shifts in the parameters which characterize the relationship in the long term and/or by identifying structural changes in the cointegration relationship itself. Based on the theoretical approach by Quintos (1995), Camarero et al. (1998) covers the period 1964-1996 and concludes that the deficit process in Spain is sustainable and exhibits the weak condition.

The second work utilizes the usual cointegration tests and introduces a univariant analysis which enables the detection of any existing changes in the order of integration in the series. It concludes that although the results derived from the cointegration analysis of the revenue and spending variables are not conclusive, series $\Delta b_{t}$ is stationary with a zero average in the partial samples considered. Thus, the transversality condition is held in the strong sense.

More recently, Martin (2000) examines sustainability using a new approach which incorporates a cointegration model with multiple endogeneous breaks. This study finds evidence of a sustainable deficit process over the course of the period 1947-1992, despite the presence of structural breaks in the 1970s and 1980s.

The definition of deficit sustainability by Hatzinikolau and Simos (2013) requires that discounted debt disappear asymptotically and that undiscounted debt be limited. Said definition gives way to a new necessary condition and a new test procedure. These authors conclude that the budget and the deficit in the United States feature current account sustainability.

\section{The Theoretical Model}

The formulation of the theoretical model is fundamentally based on Quintos (1995) and Camarero et al. (1998).

We begin with the budget constraint of the public sector for a period given by

$$
\Delta B_{t}=G_{t}-R_{t}
$$

Where $B_{t}$ is the real market value of public debt or public debt stock, $G_{t}$ is the real public expenditure including debt interests, and $R_{t}$ is the real tax revenue. The equation defines the real debt including debt interests. By defining $\mathrm{i}_{\mathrm{t}}$ as interest rate stationary around a mean $\mathrm{i}$, and $\mathrm{GE}_{\mathrm{t}}$ as the real expenditure excluding debt interest, it is possible to 
formulate $G_{t}=G E_{t}+i_{t} B_{t-1}$, where the second term represents interest payments on accumulated debt at the end of the previous period. Based on this, it is possible to define

$$
E X P_{t}=G E_{t}+\left(i_{t}-i\right) B_{t-1}
$$

This allows us to express debt as either

$$
\begin{aligned}
B_{t} & =(1+i) B_{t-1}+E X P_{t}-R_{t} \\
\text { Or as } B_{t} & =\left(\frac{1}{1+i}\right)\left(R_{t+1}-E X P_{t+1}\right)+\left(\frac{1}{1+i}\right) B_{t+1}
\end{aligned}
$$

Solving for $B_{t}$ in Equation (4) via forward substitution gives the intertemporal budget constraint of the government.

$$
B_{t}=\sum_{j=0}^{\infty}\left(\frac{1}{1+i}\right)^{j+1}\left(R_{t+j+1}-E X P_{t+j+1}\right)+\lim _{j \rightarrow \infty}\left(\frac{1}{1+i}\right)^{j+1} B_{t+j+1}
$$

Defining $\mathrm{E}_{\mathrm{t}}($.) as the expectation conditioned on the information available in time $\mathrm{t}$, the intertemporal budget balance or the sustainability of the deficit is obtained if and only if ${ }^{\text {iv }}$

$$
\lim _{j \rightarrow \infty} E_{t}\left(\frac{1}{1+i}\right)^{j+1} B_{t+j+1}=0
$$

This equation implies that the current value of the remaining public debt is equal to the present value discounted from the future budget surplus. In other words, the deficit is sustainable if and only if it is expected that a holder's debt stock will not grow faster, on average, than the average real interest rate, which can be considered an approximation of an economy's growth rate, implying

$$
B_{t}=\sum_{j=0}^{\infty}\left(\frac{1}{1+i}\right)^{j+1}\left(R_{t+j+1}-E X P_{t+j+1}\right)
$$

Using first differences in Equation (8.5) (Quintos, 1995) we obtain

$$
\Delta B_{t}=\sum_{j=0}^{\infty}\left(\frac{1}{1+i}\right)^{j+1}\left(\Delta R_{t+j+1}-\Delta E X P_{t+j+1}\right)+\lim _{j \rightarrow \infty}\left(\frac{1}{1+i}\right)^{j+1} \Delta B_{t+j+1}
$$

Which means sustainability is associated with

$$
\lim _{j \rightarrow \infty} E_{t}\left(\frac{1}{1+i}\right)^{j+1} \Delta B_{t+j+1}=0
$$

Thus far we have considered variables in absolute terms. It is also possible to conduct the analysis using budget constraints in terms of GDP. By dividing Equation (3) by $\mathrm{Y}_{\mathrm{t}}$, which represents GDP in time t, we obtain

$$
(1+n) b_{t+1}=(1+i) b_{t}+\exp _{t}-r_{t}
$$

where the variables have been divided by $Y_{t}$ and the relationship $Y_{t+1}=Y_{t}(1+n)$ has been utilized, where $n$ is the growth rate of $Y_{t}$, which is assumed to be constant.

The previous equation gives

$$
b_{t}=\frac{1}{1+i} \sum_{i=0}^{j-1} \frac{r_{t+i}-e x p_{t+i}}{(1+\gamma)^{i}}+\frac{b_{t+j}}{(1+\gamma)^{j}}
$$

Where $1+\gamma=(1+\mathrm{i}) /(1+\mathrm{n})$. Therefore, if $\mathrm{i}>\mathrm{n}, \gamma>0$ is obtained; whereas if $\mathrm{i}<\mathrm{n}, \gamma<0$ is obtained.

The previous expression can be written as differences using the following transformation

$(1+n) b_{t+1}-(1+n) b_{t}=(1+i) b_{t}-(1+n) b_{t}+\exp _{t}-r_{t}$ by which $(1+\mathrm{n})\left[b_{t+1}-b_{t}\right]=(1+i-1-n) b_{t}+$ $\exp _{t}-r_{t}$ and, therefore,

$$
\Delta b_{t}=\frac{(i-n)}{(1+n)} b_{t}+\exp _{t}-r_{t}=\lambda_{t} b_{t}+\exp _{t}-r_{t}
$$


In the opinion of De Castro (2005), variables at levels do not prove to be the most suitable for conducting a sustainability analysis. Instead, the author recommends taking the size of the economy into consideration, making it advisable to express variables as percentages of GDP, thereby focusing the analysis on the weight that public debt represents in the economy.

Following (12), and using $\lambda_{\mathrm{t}}$ as stationary around a mean $\lambda$, we can write the previous equation as

$$
\Delta b_{t+1}=\lambda b_{t}+\exp _{t}-r_{t}
$$

where $\exp _{t}=g_{t}+\left(\lambda_{t}-\lambda\right) b_{t}$. By solving forward the equation, we obtain

$$
\begin{gathered}
b_{t}=\sum_{j=0}^{\infty} \gamma^{j+1}\left(t_{t+j}-\exp _{t+j}\right)+\lim _{j \rightarrow \infty} \gamma^{j+1} b_{t+j+1} \\
\gamma^{j+1}=(1+\lambda)^{-(j+1)}
\end{gathered}
$$

By using expectations in Equation (13), the hypothesis of fulfillment of the intertemporal budget constraint of the government can be expressed as

$$
b_{t}=\sum_{j=0}^{\infty} E_{t} \gamma^{j+1}\left(r_{t+j}-\exp _{t+j}\right)
$$

Which is equivalent to the following transversality condition

$$
\lim _{j \rightarrow \infty} E_{t} \gamma^{j+1} b_{t+j+1}=0
$$

In order to conduct the empirical test we utilize the previous equation in terms of differences, with which we obtain

$$
\Delta b_{t}=\sum_{j=0}^{\infty} \gamma^{j+1}\left(\Delta r_{t+j}-\Delta \exp _{t+j}\right)+\lim _{j \rightarrow \infty} \gamma^{j+1} \Delta b_{t+j+1}
$$

Thus, the transversality condition is expressed as

$$
\lim _{j \rightarrow \infty} E_{t} \gamma^{j+1} \Delta b_{t+j+1}=0
$$

It is observed that conditions (9) and (18) are formally equivalent, meaning we can carry out reasoning using the variables at levels and extend them to the case of percentages of GDP.

The condition in Equation (9) is fulfilled when $\Delta B_{t}$ is either stationary or not stationary at the rate where the approximation to zero takes place, albeit slower in the case of non-stationarity.

Given Equation (1), and with $R_{t}$ and $G_{t}$ considered processes $I(1)$, the properties of cointegration of these processes can be utilized to understand the behavior of Equation (9).

Defining a regression model as

$$
R_{t}=\alpha+\beta E X P_{t}+u_{t}
$$

If cointegration exists in the previous equation between variables with $\beta=1$, transversality condition (9) is fulfilled because $\Delta B_{t}=O p(1)$ and, consequently, limit term (9) behaves like $E \lim _{T \rightarrow \infty} \exp (-T k)=0 \quad$ (20).

This condition is sufficient for sustainability because it is not necessary that $\Delta B_{t} \sim I(0)$ to hold (9). If $\Delta B_{t} \sim I(d)$ with $\mathrm{d}$, a finite integration order, is held

$$
E \lim _{T \rightarrow \infty} \exp (-T k) T^{d / 2}=0
$$

Therefore, if $\Delta B_{t}$ is an integrated process of any finite order, the discount factor decreases at a faster rate than the growth shown by $\Delta B_{t}$, allowing transversality condition (9) and, thus, the version of intertemporal borrowing constraint in differences to be fulfilled, albeit the limit term in (9), approaches zero at a slower rate when $\Delta B_{t}$ is $\mathrm{I}(0)$.

This brings us to the following definitions (Quintos, 1995):

A deficit process has strong sustainability if the restriction term in the transversal condition behaves the same as in (20), whereas the process has weak sustainability if the limit behaves the same as in (21).

The deficit will not be sustainable when $\Delta B_{t}$ has an explosive root of a certain magnitude which does not compensate for the discount factor. 
Strong sustainability also implies that the budget constraint is fulfilled and, at the same time, the discounted debt process $\left(\mathrm{B}_{\mathrm{t}}\right)$ is $\mathrm{I}(1)$, which means $\Delta B_{t}$ is $I(0)$. Weak sustainability implies that the constraint is fulfilled but with $\mathrm{B}_{\mathrm{t}}$ exploding at a lower rate than that of economic growth, approximated using the mean real interest rate. Although the latter situation is consistent with sustainability, it could have implications for the possible commercialization of debt and, therefore, it is the least desirable scenario. An unsustainable deficit is that in which $\mathrm{B}_{\mathrm{t}}$ is explosive at a rate that is the same as or greater than the economic growth rate, meaning it violates the intertemporal constraint of Equation (6).

Strong sustainability implies that if the current situation were to continue, it would be unlikely for problems to arise in the future which required a budget adjustment. However, a situation of weak sustainability could result in problems, specifically related to debt commercialization, which would entail possible increases in the interest rates linked to large volumes of debt emission. If debt commercialization problems were to materialize, macroeconomic stability could be compromised, consequently requiring structural fiscal reforms to redirect the course of said scenario (De Castro, 2005; Quintos, 1995; Camarero et al, 1998).

Quintos demonstrates that $\beta_{1}=1$ in Equation (10) is a sufficient condition of sustainability as it implies that the transversality condition behaves like (20). However, it is not a necessary condition, as $0 \leq \beta \leq 1$ is a necessary and sufficient condition, whereas cointegration is merely a sufficient condition.

If we substitute (19) in Equation (1), we obtain

$$
\Delta B_{t}=(1-\beta) E X P_{t}-\mu-\varepsilon_{t}
$$

If $0<\beta<1$ in (22) $\Delta B_{t}$ is $\mathrm{I}(1)$ when $E X P_{t}$ is $\mathrm{I}(1)$, independently of whether $\varepsilon_{t}$ is $\mathrm{I}(0)$ o $\mathrm{I}(1)$ (or independently of whether $\mathrm{R}_{\mathrm{t}}$ and $E X P_{t}$ are cointegrated).

Therefore, $\Delta B_{t}$ is stationary if $\beta=1$ and $\varepsilon_{t}$ is $\mathrm{I}(0)$. That is, they are necessary and sufficient in both conditions to hold (21) or, in other terms, $\Delta B_{t}$ is $\mathrm{I}(0)$.

In the case of the weak form, the necessary and sufficient conditions are a) $0 \leq \beta \leq 1$ and b) expression (20) is held. In order for (20) to be fulfilled it is sufficient that $\Delta B_{t}$ is $\mathrm{I}(1)$ or even mildly explosive, as long as the explosive roots behave as (21).

\section{An Empirical Test for Spain}

Bearing the information above in mind, the following is a suitable strategy for testing the sustainability of fiscal politics (Camarero et alt, 1998; Quintos, 1995)

1) Test the integration order of variables $\mathrm{R}_{\mathrm{t}}$ and $E X P_{t}$. If they are $\mathrm{I}(1)$, test expression (19) $R_{t}=\alpha+$ $\beta E X P_{t}+u_{t}$.

2) Test $\mathrm{H}_{0}: \beta=0$ versus $\mathrm{H}_{1}: \beta>0$.

3) If $\mathrm{H}_{0}$ is accepted, the deficit is not sustainable.

4) If $\mathrm{H}_{0}$ if rejected, test $\mathrm{H}_{0}: \beta=1$ versus $\mathrm{H}_{1}: \beta<1$.

5) If $\mathrm{H}_{0}$ is accepted and there is cointegration among the variables, the strong condition will hold, that is, the deficit exhibits strong sustainability.

6) If $\mathrm{H}_{0}$ is accepted and there is not cointegration among the variables, the weak condition will hold, that is, the deficit exhibits weak sustainability.

7) If $\mathrm{H}_{0}$ is rejected and $0<\beta<1$, the weak condition will hold despite the presence of cointegration.

The following graphs (figure 1, a, b, c, d) display spending and public revenue during the period 1960-2016 in real euros, as well as both variables and deficit and debt in terms of GDP. The source of data are Comín and Díaz Fuentes (2006) from 1960 to 2000 and National Statistics Institute. Spanish Statistical Office (INE) from 2001 to 2016. 

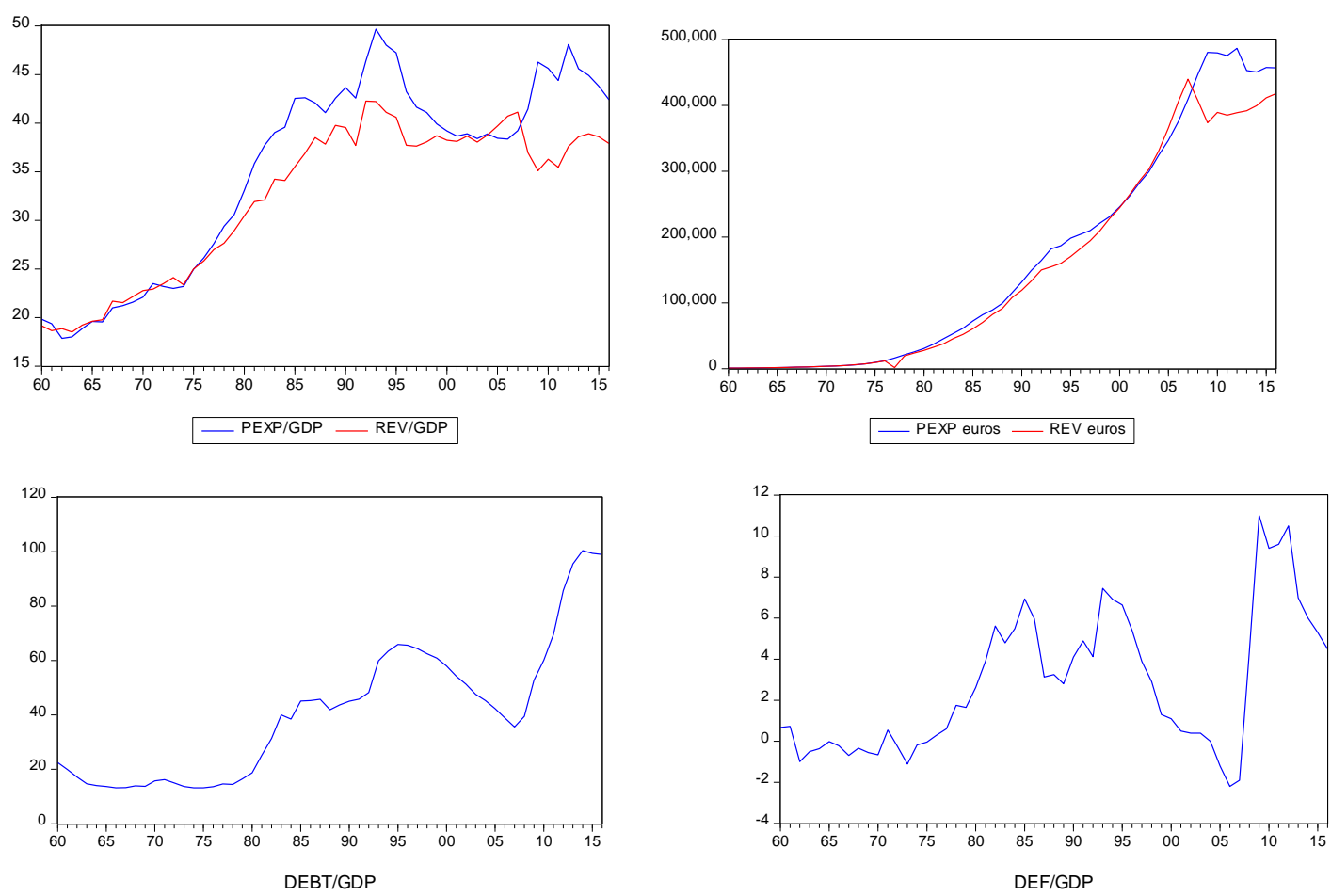

Figure 1. (a) Public Expenditure/GDP; (b) Revenue/GDP; (c) Public Debt/GDP; (d) Public Deficit/GDP

The data are taken from Comín and Díaz-Fuentes (2006) until 2000, and from the National Statistics Institute. Spanish Statistical Office. (INE, in Spanish) from 2001 to 2016. https://www.fbbva.es/wp-content/uploads/2017/05/dat/DE_2006_estadisticas_historicas.pdf and https://www.ine.es/. In both cases the data were converted into real euros utilizing the corresponding deflators. The legal link of the INE was used to combine the series. In the graph we use public expenditure (PEXP); Revenue (REV); Debt (DEBT); Deficit (DEF)

The empirical analysis has to be carried out carefully to verify the nature of the series, because if they are not stationary, problems could arise in the estimation of the regression equation coefficients. Valid estimations for the models require that data be stationary (integrated zero-order) or, if they are not stationary (integrated first-order), that they be cointegrated. More specifically, the first step will be to verify whether the variables are stationary or whether they have one or more unit roots. If they are integrated, an analysis will be made to verify the possible existence of cointegration between the two. If they are cointegrated, the relationships or cointegrating equations will be estimated. These cointegrating equations specify the long-run relationships between the variables.

When we study a long period of time, it is possible to find instances of structural change in the series. For this reason we allow structural breaks in the series in both the unit root and cointegrating tests.

These structural breaks may be the result of changes in the economy or in the different factors that affect or determine the series utilized. In this situation, if the structural changes are not taken into consideration when the existence of a long-term relationship is investigated, said relationship might not be detected when it does indeed exist.

In order to carry out said analysis, the usual cointegration tests can be implemented: Gregory-Hansen test and Hansen test. To analyze stability we use Quandt-Andrews and Bay-Perron test.

The unit roots test of the series was conducted using the strategy designed. The table 1 below indicates that in both real terms and in relation to GDP the three variables - spending, public revenue and public debt - are I(1) but are not I(2). 
Table 1. Unit root tests of the different variables in the model and their first differences

\begin{tabular}{llll}
\hline & ADF $(\mathbf{C . V})$. & PP $(\mathbf{C} . \mathbf{V})$. & KPSS (C.V.) \\
\hline $\mathbf{E X P}$ & $-1.48(-3.49)$ & $-2.09(-3.49)$ & $0.21(0.14)$ \\
$\Delta \mathbf{E X P}$ & $-3.35(-2.91)$ & $-3.55(-2.91)$ & $0.34(0.46)$ \\
\hline $\mathbf{R}$ & $-2.14(-3.49)$ & $-1.99(-3.49)$ & $0.21(0.14)$ \\
$\Delta \mathbf{R}$ & $-4.37(-2.91)$ & $-4.37(-2.91)$ & $0,36(0.46)$ \\
\hline $\mathbf{B}$ & $-1.04(-3.49)$ & $0.56(-3.49)$ & $0.22(0.14)$ \\
\hline$\Delta \mathbf{B}$ & $-5.18(-3.51)$ & $-3.23(-3.49)$ & $0.08(0.14)$ \\
\hline $\mathbf{E x p}$ & $-0.71(-3.49)$ & $-1.16(-3.49)$ & $0.18(0.14)$ \\
$\Delta \mathbf{e x p}$ & $-5.56(-2.91)$ & $-5,65(-2.91)$ & $0.18(0.46)$ \\
\hline $\mathbf{R}$ & $-0.75(-3.49)$ & $-0.73(-3.49)$ & $0.21(0.14)$ \\
$\Delta \mathbf{r}$ & $-7.21(-2.91)$ & $-7.21(-2.91)$ & $0.31(0.46)$ \\
\hline $\mathbf{B}$ & $-0.84(-2.91)$ & $0.04(-2.91)$ & $0.78(0.46)$ \\
\hline$\Delta \mathbf{b}$ & $-3.46(-2.91)$ & $-3.38(-2.91)$ & $0.16(0.46)$ \\
\hline
\end{tabular}

The tests are Augmented Dickey Fuller (ADF), Phillip-Perron (PP) and Kwiatkowski-Phillips-Schmidt-Shin (KPSS). Critical values for a $95 \%$ confidence level in parentheses

Therefore, we take into consideration the possible cointegration relationships that exist between the spending and revenue variables. For this purpose, we utilize the cointegration tests (Engle and Granger, EG and Phillips-Outlaris, PO) with a single equation and the Johansen-Juselius test $(\mathrm{JJ})$, which is based on a likelihood ratio test to determine the number of cointegration vectors in the regression. The EG and PO tests offer contradictory results. The former rejects the null hypothesis that the series are cointegrated, while the latter does not. The JJ test, table 2 , indicates that the series are cointegrated and that there is a single cointegration vector in both the trace test and the eigenvalues test.

Table 2. Johansen-Juselius test

\begin{tabular}{|c|c|c|c|c|}
\hline & Eigenvalues & Trace statistic & Critical value & Probability \\
\hline $\mathbf{r}=\mathbf{0}$ & 0.42 & 30.16 & 15.42 & 0.00 \\
\hline \multirow[t]{2}{*}{$r \leq 1$} & 0.003 & 0.18 & 3.84 & 0.66 \\
\hline & & $\begin{array}{l}\text { Eigenvalue } \\
\text { statistic }\end{array}$ & Critical value & Probability \\
\hline $\mathbf{r}=\mathbf{0}$ & & 29.97 & 14.26 & 0.00 \\
\hline$r \leq 1$ & & 0.18 & 3.84 & 0.66 \\
\hline
\end{tabular}

The critical values and the corresponding probability are available for this test. The hypothesis to test are $\mathrm{r}=0$, which indicates that no cointegration vector exists, and $r \leq 1$, which indicates that, at the most, a cointegration vector does exist.

We calculate said cointegration relationship using fully modified ordinary least squares (FMOLS), which gives

$$
\mathrm{R}=0.89 \text { EXP- } 1373.50 \text { with an } \mathrm{R}^{2} \text { equal to } 0.97 \text {. }
$$

The following values are obtained in the tests corresponding to the value of the EXP coefficient: For $\beta=1, \chi^{2}=16.93$ with a $p$-value $=0.00$ and for $\beta=0, \chi^{2}=1113.268$ with a $p$-value $=0.00$. Therefore, both null hypotheses are rejected and $0<\beta<1$ is obtained. According to this result weak deficit sustainability exists.

If we utilize the variables in relation to GDP, we obtain the following results: In the first two tests ( EG and OP) the null hypothesis of no cointegration between the variables cannot be rejected, while the third (JJ) shows both tests indicate that there not cointegration between the variables (table 3). 
Table 3. Johansen-Juselius Test

\begin{tabular}{lllll}
\hline Johansen-Juselius & Eigenvalues & Trace statistic & Critical value & Probability \\
\hline $\mathbf{r}=\mathbf{0}$ & 0.19 & 18.68 & 20.26 & 0.08 \\
$\mathbf{r} \leq \mathbf{1}$ & 0.12 & 7.10 & 9.16 & 0.12 \\
\hline & & eigenvalues & Critical value & Probability \\
& & statistic & \\
\hline $\mathbf{r}=\mathbf{0}$ & 11.58 & 15.89 & 0.21 \\
\hline $\mathbf{r} \leq \mathbf{1}$ & & 7.10 & 9.16 & 0.12 \\
\hline
\end{tabular}

The critical values and the corresponding probability are available for this test. The hypothesis to test are $\mathrm{r}=0$, which indicates that no cointegration vector exists, and $r \leq 1$, which indicates that, at the most, a cointegration vector does exist.

Based on this result, we analyze the value of coefficient $\beta$ in the previous equation. Given the lack of cointegration between the variables, we opted to carry out an OLS test for first differences of the series. The coefficient obtained is equal to 0.31 and is clearly different from zero and one, which would indicate that, according to this criterion, the deficit exhibits weak sustainability.

Taking into account the characteristics of the series, the extensive period of time considered and the evolution of the Spanish economy during that time, it is plausible to conjecture that structural breaks occurred in the model variables. Thus, we conduct tests utilizing unit roots and cointegration with structural breaks.

The results of the different tests indicate that the three variables, both in real terms and in percentages of GDP, are I(1) and not I(2), albeit the breakpoints oscillate between the end of the 1970s for revenue, the second half of the 1980s and the 1990s for spending, and the end of the 1980s and 2008 for debt (Table 4).

Table 4. Unit root test with structural breaks

\begin{tabular}{|c|c|c|c|}
\hline & BADF (C.V.) & P (C.V.) & Z-A (C.V.) \\
\hline \multirow[t]{2}{*}{$\mathbf{R}$} & $1997-3.08(-4.85)$ & $1978-2.99(-5.59)$ & $1979-2.92(-5.08)$ \\
\hline & $-10.08(-4.85)$ & $-10.32(-5.59)$ & $-6.53(-5.08)$ \\
\hline \multirow[t]{2}{*}{ EXP } & $1966-2.33(-4.85)$ & $1985-2.90(-5.59)$ & $1986-2.82(-5.08)$ \\
\hline & $-7.58 \quad(-4.85)$ & $-5.82(-5.59)$ & $-6.53(-5.59)$ \\
\hline \multirow[t]{2}{*}{ B } & $2008-3.03(-4.44)$ & $2008-4.51(-5.23)$ & $2008-4.03(-4.91)$ \\
\hline & $-9.97(-4.44)$ & $-10.23(-5.23)$ & $-7.36(-4.93)$ \\
\hline \multirow[t]{2}{*}{$\mathbf{R}$} & $1978-2.36(-4.85)$ & $1985-3.42(-5.59)$ & $1975-2.28(-4.93)$ \\
\hline & $-8.22(-4.44)$ & $-6.84(-5.23)$ & $-6.82(-4.93)$ \\
\hline \multirow[t]{2}{*}{ Exp } & $1995-3.32(-4.85)$ & $1995-3.31(-5.23)$ & $1996-3.30(-4.93)$ \\
\hline & $-6.47(-4.44)$ & $-6.48(-5.23)$ & $-6.82(-4.93)$ \\
\hline \multirow[t]{2}{*}{$\mathbf{B}$} & $1989-3.33(-4.44)$ & $1999-3.03(-5.23)$ & $1996-4.49(-4.93)$ \\
\hline & $-4.98(-4.44)$ & $-5.54(-5.23)$ & $-5.10(-4.93)$ \\
\hline
\end{tabular}

The unit root tests used were Breakpoint ADF (BADF), Perron (P) and Zivot-Andrews (Z-A). In each case, the test endogenously detected a breakpoint

In order to analyze the possible cointegration relationship we utilize cointegration tests with structural breaks. Firstly, the Gregory-Hansen test (table 5) can endogenously detect the existence of structural breaks in the equation, as well as any possible cointegration between the variables. The results obtained indicate that there only exists cointegration in the case of R-EXP, considering the constant and the trend.

Table 5. Gregory-Hansen test

\begin{tabular}{llll}
\hline & \multicolumn{2}{l}{ Constant } & \multicolumn{1}{l}{ Constant+trend } \\
\hline R-EXP & 1994 & $-3.64(-4.61)$ & $2001-5.46(-4.95)$ \\
\hline r-Exp & 1982 & $-3.28(-4.61)$ & $2000-4.51(-4.95)$ \\
\hline
\end{tabular}


The estimation was conducted using a fictitious variable which takes the value of zero for the years prior to 2001 and the value of one after $2001^{\mathrm{v}}$. The result is the following:

$$
\mathrm{R}=0.81 \mathrm{EXP}+31,498.21 \mathrm{D} 2001+2252 \text { with } \mathrm{R}=0.98 \text {. }
$$

For tests $\beta=1, \chi^{2}=16.93$ with a $p$-value $=0.00$ and $\beta=0, \chi^{2}=1113.268$ with a $p$-value $=0.00$. Therefore, both null hypotheses are rejected and $0<\beta<1$ is obtained. According to this result, the deficit exhibits weak sustainability.

In order to analyze any possible instability we utilize the Hansen test (table 6) which indicate that the series are cointegrated and the null of stability in the relationships cannot be rejected, as Prob>0.2.

Table 6. Hansen test

\begin{tabular}{lllll}
\hline & Stochastic trends & Deterministic trends & Excluded trends & Probability \\
\hline R-EXP & 1 & 0 & 0 & $>0.2$ \\
\hline r-exp & 1 & 0 & 0 & $>0.2$ \\
\hline
\end{tabular}

The null hypothesis is the existence of cointegration against the alternative of no cointegration. Hansen notes that under the alternative hypothesis of no cointegration, one should expect to see evidence of parameter instability.

We also conducted complementary diagnostics using the Quandt-Andrews and Bai-Perron tests to analyze stability. In the case of the variables in real terms, we found a structural break in 2006 when applying the first test, while with the Bai-Perron multiple breakpoint test we detected two breaks - one in 1997 and another in 2008. Bearing in mind that 2008 is very close to the end of the sample people, it could be considered that there is merely one breakpoint in 1997. This break can be represented by a fictitious variable D1997, which takes the value of zero for the years prior to 1997 and the value of one after said year. The estimation of the formulated model thus gives

$$
\mathrm{R}=0.76 \mathrm{EXP}+51.98 \mathrm{D} 1997+2651 \text { with } \mathrm{R}^{2}=0.98
$$

For tests $\beta=1, \chi^{2}=27.53$ with a $p$-value $=0.00$ and $\beta=0, \chi^{2}=27.00$ with a $p$-value $=0.00$. Therefore, both null hypotheses are rejected and $0<\beta<1$ is obtained. According to this result, the deficit exhibits weak sustainability.

As an alternative to the previous process, we considered the possibility of restricting the sample period to 1960-1997. In the estimation of the equation, the following result is obtained

$\mathrm{R}=0.89$ EXP -2.48 with $\mathrm{R}^{2}=0.99$. For tests $\beta=1, \chi^{2}=27.53$ with a $\mathrm{p}$-value $=0.00$ and $\beta=0, \chi^{2}=27.00$ with a $\mathrm{p}$-value $=$ 0.00 . Therefore, both null hypotheses are rejected and $0<\beta<1$ is obtained. According to this result, the deficit exhibits weak sustainability.

There is a structural break in 1987 for both $\mathrm{r}$ and exp when using the Quandt and Andrew test, while the Bai-Perron test detects structural breaks in 1987 and 1993. The following estimation is obtaining by utilizing the breakpoint in 1987

$$
\mathrm{r}=0.61 \mathrm{exp}+3.52 \mathrm{D} 1987+9.00 \text { with } \mathrm{R}^{2}=0.93
$$

For tests $\beta=1, \chi^{2}=27.53$ with a $p$-value $=0.00$ and $\beta=0, \chi^{2}=27.00$ with a $p$-value $=0.00$. Therefore, both null hypotheses are rejected and $0<\beta<1$ is obtained. According to this result, the deficit exhibits weak sustainability.

Considering only the period 1960-1987, we obtain

$$
\mathrm{r}=0.72 \exp +6.13 \text { with } \mathrm{R}^{2}=0.98
$$

For tests $\beta=1, \chi^{2}=123.04$ with a $p$-value $=0.00$ and $\beta=0, \chi^{2}=851.58$ with a $p$-value $=0.00$. Therefore, both null hypotheses are rejected and $0<\beta<1$ is given. According to this result, the deficit exhibits weak sustainability. 
The result obtained for series $\Delta \mathrm{b}$ is similar to that obtained previously, considering possible cointegration between revenue and spending. Said series is I(1), that is, non-stationary, which means it fulfills the conditions in order that the deficit sustainability will be weak sustainibility.

\section{Conclusions}

The present study analyzes the sustainability of Spain's public deficit in the period 1960-2016 by considering public revenue and spending in real terms, as well as in percentages of GDP. To do so, it analyzes the possible cointegration between both variables and the possible value of the public spending coefficient in the estimation between both variables. The results systematically reject any cointegration between the variables and, in the cases where it is accepted, the equality of coefficient $\beta$ to zero or one is rejected. In general, $0<\beta<1$ is obtained, meaning the deficit exhibits weak sustainability. As the numerous authors mentioned in the text state, weak sustainability implies that governments could experience difficulty commercializing their debt in the future. This type of scenario would involve a substantial risk of interest rate increases that could have dramatic effects on economic growth and budget balances, which, in turn, would require fiscal reforms or, at least, an overall consolidation effort.

The actual evolution of Spain's debt is very much in keeping with the aforementioned assessment. The Great Recession of 2008 made investors question the stability of Spain's public finances. The restrictive policies of the European Union and the constraints of the European Central Bank created a precarious situation for Spanish debt, marked by a high interest rate differential with respect to the German bund (risk premium) which reached a maximum of 574 basic points by mid-2012. This situation led to a severe drain on Spain's public treasury, which continued until commitment to massive purchases of public and private debt in Spain and other European countries (by European Central Bank) became a reality.

These budget deficits continued the following years (5.97\% in 2014, 5.28\% in 2015 and 4.51\% in 2016), during which time there was a slight increase in GDP.

While the economic authorities have made numerous attempts to successfully balance the budget, urged to do so by the EU, the fact remains that given the low growth in GDP, the deficient Spanish taxation system combined with high expenditure needs have brought about the previously mentioned deficits.

The Covid-19 crisis has revealed the Spanish economy's weaknesses, both internally and in relation to the rest of the European economies. In 2019, Spain's GDP grew 2\% compared to 2018, with a public deficit of 2,7\% of GDP. However, in 2020, the impact of the pandemic has caused the GDP to fall 5.2\% in the first trimester and $17.8 \%$ in the second. The GDP is expected to decrease in 2020 by $18,5 \%$. The expected deficit is $14,4 \%$ of GDP.

\section{References}

Alcaide, J. (1988). El gasto público en la democracia española. Los hechos. Papeles de Economía Española, 37, 2-17.

Camarero, M., Esteve, V., \& Tamarit, R. (1998). Cambio de régimen y sostenibilidad a largo plazo de la política fiscal: el caso de España. Instituto Valenciano de Investigaciones Económicas. Documento de Trabajo WP-EC 98-15.

Comín, F., \& Díaz-Fuentes, D. (2006). Sector público administrativo y estado del bienestar". Estadísticas históricas de España. Siglos XIX-XX. (p. 873-966). Fundación BBVA. Madrid. España.

Correia, M. R., Neck. R., Panagiotidis, T., \& Richter, C. (2008). An empirical investigation of the sustainibility of the public déficit in Portugal. International Economics and Economic Policy, 5(1), 209-223. https://doi.org/10.1007/s10368-008-0105-0

Council of the European Communities (1992) Treaty on European Union. Retrieved from https://europa.eu/european-union/sites/europaeu/files/docs/body/treaty_on_european_union_en.pdf

De Castro, F. (2005). Una evaluación macroeconométrica de la política fiscal en España. Banco de España. Estudios económicos, 76, 88.

European Commmision. (1997). Stability and growth pact. Retrieved from https://ec.europa.eu/info/business-economy-euro/economic-and-fiscal-policy-coordination/eu-economic-governanc e-monitoring-prevention-correction/stability-and-growth-pact_en

García Delgado, J. L. (2015). Etapas y rasgos definidores de la industrialización española. In García Delgado (2015) (dir): Lecciones de Economía española. Civitas. Madrid. España 448p.

González, M. (dir) (2013). Temas de economía española. Ed, Tirant lo Blanc libros, Valencia, España, 286p.

Hakkio, C. S., \& Rush, M. (1991). Is the Budget déficit too large? Economic inquiry, 24, 429-445. https://doi.org/10.1111/j.1465-7295.1991.tb00837.x

Hamilton, J. D., \& Flavin, M. A. (1986). On the limitations of government borrowing: a framework for testing. 
American Economic Review, 76, 808-819. https://doi.org/10.3386/w1632

Hatzinikolau, D., \& Simos, T. (2013). A new test for deficit sustainability and its application to US data. Empirical Economics, 45, 61-79. https://doi.org/10.1007/s00181-012-0607-z

Haug, A. (1991). Cointegration and government borrowing constraints: evidence for the United States. Journal of business and economic statistics, 9, 97-101. https://doi.org/10.1080/07350015.1991.10509831

Instituto Nacional de Estadística. National Statistics Institute. Spanish Statistical Office (INE, 2001-2016): Cuentas anuales no financieras de los sectores institucionales. Retrieved from https://www.ine.es/dyngs/INEbase/es/operacion.htm?c=Estadistica_C\&cid=1254736177054\&idp=1254735576581 $\& m e n u=$ resultados\#!tabs-1254736195672

Martin, G. (2000). U.S. déficit sustainability: a new approach based on multiple endogenous breaks. Journal of Applied Econometrics, 15, 83-105. https://doi.org/10.1002/(SICI)1099-1255(200001/02)15:1<83::AID-JAE543>3.0.CO;2-J

Quintos, C. E. (1995). Sustainability of the Deficit Process with Structural Shifts. Journal of Business \& Economic Statistics, 13, 409-417. https://doi.org/10.1080/07350015.1995.10524615

Serrano, J. M., \& Bandrés. E. (2019). Sector público. (Public sector). En: García, J. L. y Myro, R. (2019) (eds): Lecciones de economía española p. 291-312. Civitas-Thomson Reuters, Madrid. España.

Smith, G. W., \& Zin, S. E. (1991). Persistent deficits and market value of government debt. Journal of Applied Econometrics, 6, 31-44. https://doi.org/10.1002/jae.3950060104

Tamames, R. (2005): Introducción a la economía española. Alianza Editorial. Madrid. España, 576p.

Trehan, B., \& Walsh, C. E. (1988). Common trends, the government's budget constraint, and revenue smoothing. Journal of Economic Dynamics and Control, 12, 425-444. https://doi.org/10.1016/0165-1889(88)90048-6

Trehan, B., \& Walsh, C. E. (1991). Testing intertemporal budget constraings: theory and applications to U.S. federal budget and current account déficits. Journal of Money, Credit and Banking, 23, 291-306. https://doi.org/10.2307/1992777

Valle, V. (1996). La hacienda pública de la democracia española. Principales rasgos. Papeles de Economía Española, 68, $2-9$.

Wilcox, D. (1989). The sustainability of government déficits: implications of the present-value borrowing constraint. Journal of Money, Credit and Banking, 21, 291-306. https://doi.org/10.2307/1992415

\footnotetext{
${ }^{\text {i }}$ Note 1. In Spain, between 1939 and 1975, there was a totalitarian regime which assumed power following the victory of General Franco in the Spanish Civil War (1936-1939).

ii Note 2. Following the ratification of the Constitution in 1978, a gradual decentralization of the public sector took place. The result was the creation of the Spanish Autonomous Regions, which are the equivalent of landers in Germany or states in the U.S.A. The main difference is that their competences are limited to spending and do not include revenue (tax collection), except for several taxes with minor collection power (e.g. property tax, estate tax and gift tax).

${ }^{\text {iii }}$ Note 3. Countries of the European Economic Community

iv Note 4. This term must be zero to prevent the government from being able to continually finance their deficit with new debt, for example, by means of a Ponzi scheme.
}

${ }^{v}$ Note 5 . We use fully modified ordinary least squares (FMOLS)

\section{Copyrights}

Copyright for this article is retained by the author(s), with first publication rights granted to the journal.

This is an open-access article distributed under the terms and conditions of the Creative Commons Attribution license which permits unrestricted use, distribution, and reproduction in any medium, provided the original work is properly cited. 